\title{
IS GUARANTEE OF ORIGIN REALLY AN EFFECTIVE ENERGY POLICY TOOL IN EUROPE? A CRITICAL APPROACH
}

\author{
ÁKOS HAMBURGER \\ PhD student, Doctoral School of Business and Management, \\ Corvinus University of Budapest, Hungary \\ Email: akos.hamburger@uni-corvinus.hu
}

\begin{abstract}
Guarantees of origin are tradeable energy certificates defined by directives 2009/28/EC and 2018/2001/EU of the European Union. They serve the aim of informing final consumers on energy sources used for their electricity supply. They are also expected to encourage new investments in renewable electricity generation. This paper investigates how the use of guarantees of origin meets these expectations. A literature review, an analysis of related regulations and an evaluation of empirical data shows that there are regulatory failures both at national and the European Union levels. Furthermore, due to a contradiction between certain rules in European Union level regulation, consumers receive unreliable information on their electricity consumption mix. Therefore, although national rules should be improved, the problem of reliability cannot be resolved until the Union level framework is modified. Furthermore, the present framework does not incentivise investments in renewable energy technologies either. Accordingly, recommendations are formulated for policy makers to ensure reliable and sufficient operation of the certificate system.
\end{abstract}

Keywords: renewable energy, guarantee of origin, tradeable energy certificate, EU2020 goals

JEL-codes: Q42, Q48 


\section{INTRODUCTION}

As the environmental challenges of human activities became increasingly distressing in the last decades of the $20^{\text {th }}$ century, a significant consumer demand emerged for sustainable products (Pogutz - Micale 2011). Several market actors have been striving to satisfy this demand, even in the energy sector which is one of the most polluting industries (Stern 2007). Besides energy saving, utilizing renewable energy sources (RES) is one of the most important steps towards a sustainable energy sector. However, in the case of energy it is impossible to track energy flows through the grid, therefore it has been challenging to improve green products for consumers. First, market actors attempted to use unique solutions to prove that their energy supplied is of renewable origin. Later, more and more countries introduced regulations on reporting the origin of energy; most of them refer to some kind of tradeable certificate. Such tradeable certificates for tracking energy attributes exist in Europe (Gkarakis - Dagoumas 2016), in the United States (Gillenwater 2008), and also in Asian countries (Kumar - Agarwala 2013; Chuang et al. 2018). Certificates of this kind are suitable to support renewable or green energy products of suppliers. This paper focuses on guarantees of origin (GOs), a tool for tracking electricity attributes used in the member states of the European Union (EU) and some other European countries.

GOs were first introduced in the legislation of EU by directive 2001/77/EC. The first and still effective definition of GOs was set in Article 2 of directive 2009/28/EC (the Renewable Energy Directive): “an electronic document which has the sole function of providing proof to a final customer that a given share or quantity of energy was produced from renewable sources". The definition of GOs also refers to an obligation set in Article 3(9) of directive 2009/72/EC (the Electricity Market Directive) that forces electricity suppliers "to inform their consumers on the contribution of each energy source to the overall fuel mix of the supplier over the preceding year". This obligation is known as the 'disclosure' obligation and usually GOs are used to verify the content of disclosure. Beside this, another aim of using GOs is formulated in the Renewable Energy Directive: "it is appropriate to allow the emerging consumer market for electricity from renewable energy sources to contribute to the construction of new installations for energy from renewable sources" (22). Furthermore, the European Commission declares that an EU wide standardized system of GOs can "help Member States develop their renewable energy resources in the most cost effective manner possible" (EC 2008); and also that a functioning GO market "could help supplement or possibly in the longer term supersede public support for renewable energy” (EC 2016a: 152). Therefore, GOs should serve two policy aims: (i) informing final consumers; and (ii) drive new investments 
in renewable energy generation. This paper aims to examine how the usage of GOs meets these goals.

This topic is related to the latest legislator outcomes in the EU. The 'Clean Energy for all Europeans' package issued by the European Commission - among many others - covers the above mentioned orders of the Renewable Energy Directive and the Electricity Market Directive as well (EC 2016b; EC 2016c). A new directive on the promotion of the use of energy from renewable sources already entered into force in December 2018. Furthermore, amendments to the Electricity Market Directive and other regulations of the package were adopted by the European Parliament on the $18^{\text {th }}$ of January 2019. However, the Renewable Energy Directive and the Electricity Market Directive will remain in effect for a few years.

The structure of this paper can be outlined as follows. Section 2 provides an overview on the evolution of regulation and market of GOs. Section 3 summarizes the challenges regarding GOs based on a review of the literature and also highlights a contradiction between EU level regulations. The review is based on articles published in peer reviewed scholarly journals, as these papers provide grounded, methodologically proper results and conclusions. Beside these papers, however, policy documents were also used for the review, since the regulatory frameworks for GOs in European countries were constructed and have been continuously improved in the last two decades and such policy documents provided important background and analysis for these rules. Databases and library services were also used for the search (www.sciencedirect.com, www.emeraldinsight. com, www.ebsco.com). Keywords for the literature search were 'guarantee(s) of origin', 'renewable/green energy/electricity certificate(s)', 'energy/electricity consumption/consumer(s)', 'electricity disclosure'. The literature review is based on papers published after 2001, when GOs were first introduced in EU level regulation. Since the regulation was changed in 2009, a special focus was set on papers published after 2009. Section 4 provides results from an empirical analysis on the international flows of electricity and GOs. Section 5 includes some policy recommendations. Finally, Section 6 presents conclusions.

\section{EVOLUTION OF GREEN ELECTRICITY MARKETS}

Verifying the renewable origin of supplied electricity with tradeable certificates is a well-known practice today. In most European countries, GOs are used for this purpose. A number of papers have already described the approach and methodology of the GO system (e.g. Raadal et al. 2009; Bröckl et al. 2011; Gkarakis - Dagoumas 2016). Briefly, all GO systems throughout Europe are designed as follows: one GO refers to one MWh of electricity generated; GOs are issued in 
an electronic registry; market participants as account holders are able to transfer GOs in the registry separately from physical or business flows of electricity; GOs should be cancelled from the registry in order to prove the origin of electricity supplied to a consumer.

However, at the time when consumer demand for renewable electricity appeared in Europe, this tool had not been created yet. The first renewable power products appeared at the end of the 80s and during the 90s in European countries, such as the United Kingdom, Switzerland, Germany, the Netherlands, Sweden or Finland (Wüstenhagen et al. 2000; Lipp 2001; Salmela - Varho 2005; Markard Truffer 2006; Wüstenhagen - Bilharz 2006). These early products were usually introduced through market initiatives and this activity was not regulated in the beginning. The first system based on tradeable certificates was established only in 1998 in the Netherlands (Bertoldi - Huld 2006). The EU also did not have any regulation on renewable electricity products in the 90s. Later, recognizing the emerging consumer demand for renewable electricity (EC 2000), directive 2001/77/EC introduced the concept of GO, and forced member states to ensure that a GO is issued upon request. According to directive 2001/77/EC, GOs were not necessarily tradeable certificates. Nevertheless, the approach of tradeable certificates became so widespread that the Association of Issuing Bodies (hereafter AIB) was established as a cooperation of several national bodies in 2002. AIB aimed for cooperation and harmonization among its members and for this purpose introduced the European Energy Certificate Scheme (EECS) that contains common rules, methodology and standard for GOs (AIB 2018).

In the meantime, the progress of market liberalization and the first steps towards a common European energy market began. Several papers have already discussed this evolution (e.g. Jamasb - Pollitt 2005; Joskow 2008). As an important part of liberalization, consumers became able to freely choose among offers of electricity suppliers. Directive 2003/54/EC aimed to promote competition and help consumer choices, as it obligated electricity suppliers to disclose their energy mix to consumers. Directive 2003/54/EC still did not contain reference to GOs regarding the disclosure obligation, however, some member states recognized that this obligation could be best managed with the help of GOs.

2009 was an important milestone in the evolution of the EU legislation regarding the renewable energy sector and moving toward the common European energy market as well. Both 2001/77/EC and 2003/54/EC directives were repealed and the still effective Renewable Energy Directive and Electricity Market Directive entered into force. Regulation on disclosure obligation remained unchanged in the Electricity Market Directive. Contrary, the Renewable Energy Directive brought several new and more detailed rules for GOs. This directive introduced the definition and the purposes of GOs that were presented in Section 1. From this point in 
time, GOs became tradeable electronic certificates by definition with the standard size of $1 \mathrm{MWh}$ and containing specific information set in Article 15 of the directive. This specific information refers to the attributes of energy production (e.g. energy source, production period, information on the installation where the energy was produced). Article 15(9) of the Renewable Energy Directive also declares that member states "shall recognise guarantees of origin issued by other Member States". (It should be remarked that directives 2004/8/EC and 2012/27/EU introduced GOs for electricity generated with high efficient co-generation technology. In this article, however, high efficient co-generation GOs are disregarded.)

Meanwhile, the consumer market for renewable electricity products has gone through a significant increase. GOs served as a basis for renewable electricity products. Consumers have had the opportunity to choose among several such products in a number of countries (van der Linden et al. 2004; Lise et al. 2007; Bröckl et al. 2011; Kaenzig et al. 2013; Hast et al. 2015; Mulder - Zomer 2016). Not only households, but also corporate consumers show interest for GOs as they can use them for carbon accounting purposes (Csutora - Harangozó 2017) or for marketing communication. According to data from the AIB website, the amount of electricity verified by GOs has increased a hundredfold between 2002 and 2018. In the years between 2015 and 2018, the most GOs were issued in Norway, Italy and Switzerland. The most GOs were cancelled for consumers in Germany during this period. Figures 1 and 2 provide an overview on this market. Several papers tried to identify the existing market price premiums or the willingness-to-

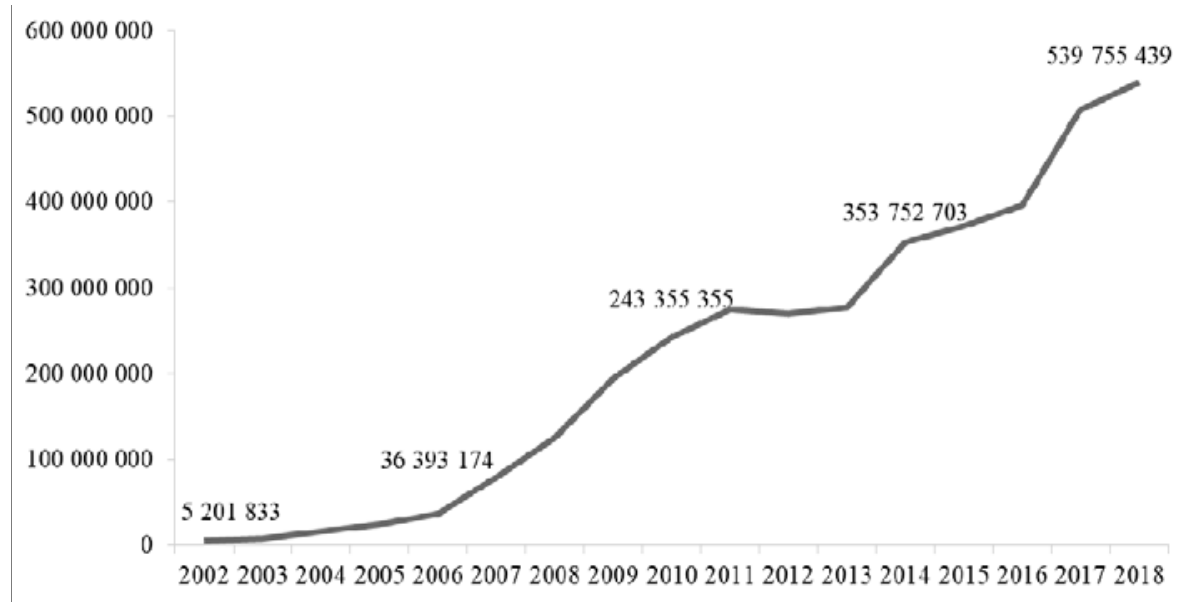

Figure 1. Number of GOs used per year in AIB member states 

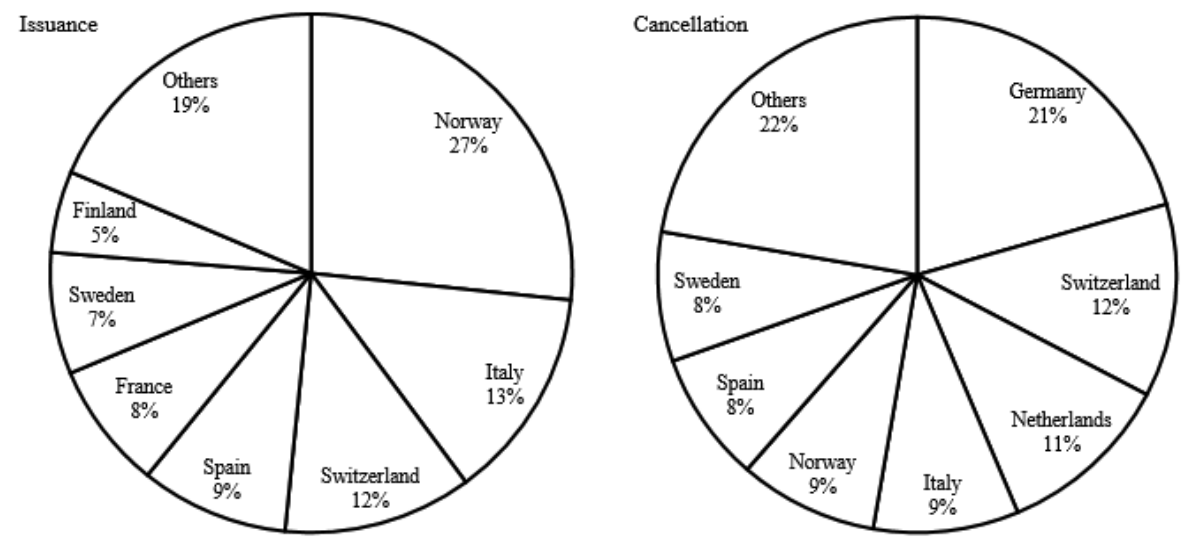

Figure 2. Share of issued and cancelled GOs between 2015-2018

Source: AIB (2019).

pay for green electricity products (eg. Zoric - Hrovatin 2012; Hast et al. 2015; Mulder - Zomer 2016; Dagoumas - Koltsakis 2017). Although they found that the market premium for such tariffs is very low, it is a fact that the total value of the European GO market is estimated to be around 120 million Euro in year 2016 (Jansen 2017).

The new directive 2018/2001/EU on the promotion of the use of energy from renewable sources that should be implemented by member states by the $30^{\text {th }}$ of June 2021 contains more sophisticated regulations on GOs, however, the basic conceptual framework did not change.

\section{DOES THE USAGE OF GOS FIT WITH POLICY GOALS?}

\subsection{Informing final consumers}

The Renewable Energy Directive prescribes that the sole function of GOs is to inform final consumers about the origin of electricity and also defines some fundamental criteria national frameworks should be based on. These fundamental criteria are the following: (i) specific rules on the data content of GOs; (ii) trade of GOs independently from physical flows should be enabled; (iii) international trade of GOs should be enabled. These fundamental rules will remain, according to directive 2018/2001. According to (iii), the EU is a common market for GOs where no limitations may occur which hinder international trade. Some non-EU countries, 
Iceland, Norway, Switzerland, also adopted EU regulations on GOs, therefore market participants of these countries are also able to act on this market.

It is obvious that the reliability and accuracy of disclosure information verified by GOs is crucial. An important issue identified by researchers is to avoid the double counting of any electricity amount (Raadal et al. 2009; Klimscheffskij et al. 2015). This problem may occur because while GOs are not issued for every MWh of electricity produced, disclosure obligation of suppliers refers to all electricity consumed. Therefore, disclosure statements are partly based on statistical energy generation mix data beside GOs. If a supplier uses GOs to verify the origin of an electricity amount, this amount should be subtracted from energy statistics. Otherwise one amount of RES electricity would be taken into account twice: once with GOs and once in the statistics. This modified energy mix not containing those electricity amounts GOs were issued for, is called the residual mix. The residual mix is an important tool: for consumers who do not choose green electricity covered by GOs, this residual mix should be presented as disclosure information. EU funded projects E-TRACK and RE-DISS formulated recommendations and protocols for a proper methodology to avoid double counting. Details are assessed by Draeck et al. (2009) and RE-DISS (2015). An important point in this regard is the fact that if a portion of GOs are used for a certain consumer, the share of RES in the residual mix will be less because the GOs used should be extracted from the energy mix. Also, if GOs are exported to another country, the domestic residual mix will become less green.

Some papers, however, drew attention to methodological or regulatory failures that cause double counting or endanger the reliability of disclosure information in other ways. Draeck et al. (2009) analysed the regulation of 29 European countries (EU27, Norway, Switzerland) and some problems were identified in all cases without exception. The RE-DISS project still found a number of discrepancies in its final report (2015) published six years later. Namely, among the 31 European countries that were subject to the report, 11 still had not implemented the disclosure regulation of the Electricity Market Directive and 20 had not implemented any rules of the Renewable Energy Directive on GOs. Other papers focus only on one or a few countries. Boardman and Palmer (2007) found a number of peculiarities in the United Kingdom that hamper consumer choice and also result in unreliable information. Eight years later Hast et al. (2015) stated that double counting of electricity still happens in the United Kingdom due to defects of legislation. This issue, together with confusing information techniques of the suppliers, results in a lack of trust that blocks the rise of demand for renewable electricity tariffs. Trust, however, is crucial for marketing renewable electricity products (Hanimann et al. 2015). Bröckl et al. (2011) focus on Nordic countries 
(Denmark, Finland, Iceland, Norway, Sweden) and conclude that other unregulated tools used to track electricity beside GOs also make it impossible to publish reliable information and to avoid double counting. Winther and Ericson (2013) point out that Norwegian disclosure information are incomprehensive and therefore often unreliable. Categories "unknown" or "import" also appear among the energy sources in the disclosure statement, due to inadequate methodology that cannot identify the share of all energy sources.

The issue of reliability becomes more complex considering Article 15(9) of the Renewable Energy Directive that obliges member states to recognize GOs from other member states. According to this paragraph, the international trade of GOs on the common European market should be enabled. Considering the issue of residual mixes, in such a framework of international GO trade, double counting could be avoided and reliable information could be provided only if national rules were harmonized. This goal is served by the activity of AIB, whose member organizations have already harmonized their regulations on GOs according to the common EECS rules. The E-TRACK and RE-DISS projects have recommended a wide harmonization among states concerned (Draeck et al. 2009; RE-DISS 2015). Several scholarly papers also declare that harmonized national regulations are needed to ensure reliable information for consumers and to avoid double counting and other discrepancies (Lise et al. 2007; Raadal et al. 2009; Bröckl et al. 2011; Gkarakis - Dagoumas 2016). Stakeholder organizations suggest harmonization too (BEUC 2015; Jansen 2017).

However, full harmonisation among EU countries has still not been realized. AIB has member organizations only from 21 countries (Austria, Belgium, Croatia, Cyprus, Czech Republic, Denmark, Estonia, Finland, France, Germany, Iceland, Ireland, Italy, Lithuania (since June 2018), Luxembourg, Netherlands, Norway, Slovenia, Spain, Sweden, Switzerland), of which 17 are members of the EU. Thus, there are no member organizations in the AIB for 10 member states (Bulgaria, Greece, Hungary, Latvia, Malta, Poland, Portugal, Romania, Slovakia, United Kingdom). Therefore, particular rules in national legislation still differ and different methodologies result in double counting and other discrepancies (Klimscheffskij et al. 2015; Jansen 2017).

The issues discussed above (discrepancies, incomprehensive information, double counting, lack of harmonization) could be handled with the improvement of regulation and methodology. In some cases, the necessary improvements might have happened since the publication of the cited papers. However, some papers identify quite different concerns regarding the reliability of GO information. Aasen et al. (2010) focus on Norwegian corporate consumers of renewable electricity tariffs and conclude that the consumers do not really trust the GOs and dis- 
closure information. Their mistrust is not a result of an insufficient methodology (e.g. double counting, lack of harmonization), but the fact that physical electricity cannot be tracked. Winther and Ericson (2013: 378) analysed the attitude of Norwegian household consumers and points out that "people's conceptualisation of electricity in terms of its physical characteristics and the issue of tracing were important barriers in making them understand and believe in the information". Both papers draw attention to a peculiar speciality of Norway in this regard. Namely, Norwegian consumers are aware of the fact that the entire electricity production of Norway is renewable. Despite this well-known fact, many consumers are informed through disclosure that they consume electricity generated from fossil sources. This can occur because a large amount of Norwegian GOs are exported to other countries and therefore the local consumption is covered with a residual mix. This residual mix of the Norwegian consumption contains fossil fuels as well, coming from other countries. (The methodology used in this case is assessed by the RE-DISS (2015) project.) The same problem was also referred to by Bröckl et al. (2011) for Iceland. The case of Iceland is especially remarkable, because this land has no physical interconnectors to other countries.

Research papers identify three issues regarding information based on GOs:

- inadequate national regulations and methodologies that endanger reliability and accuracy (e.g. through double counting);

- lack of harmonization between countries that also results in unreliable information for consumers in the case of international GO trade;

- incomplete consumer understanding and acceptance of information based on GOs due to their knowledge on physical electricity.

However, none of these papers draw attention to one serious inconsistency in the EU level regulation. According to the Renewable Energy Directive, all member states should reach a predefined binding target by 2020 regarding the share of RES in the energy supply. GOs enable the trade of electricity attributes between member states, and consumers are informed about their electricity consumption based on GOs. However, Article 15(2) of the Renewable Energy Directive declares that GOs traded internationally "shall have no function in terms of a Member State's compliance with” the 2020 goals. Similarly, Regulation No. 1099/2008 of the European Parliament and of the Council on energy statistics also does not specify any opportunity to include GOs in official energy statistics. Therefore, a consumer choice for renewable electricity does not appear in any official statistic nor have any effect on official national energy mixes. Consumers get disclosure information from the supplier but officially another statement is generated. If any amount of GOs become traded internationally, the two statements will surely contain different information. On one hand, it is reasonable that 
the EU legislation does not allow national achievements in RES development financed by costly support schemes or investment subsidies to vanish through exporting GOs by market participants. If a member state makes a lot of effort to reach a binding target, it would not be acceptable that unregulated voluntary demand for certificates defeats the outcome. However, it is clear that this inconsistency within EU rules endangers the trustworthiness of disclosure information. Accordingly, the following questions might be raised: does disclosure provide only fictive information; are the consumers who choose RES electricity and pay a price premium aware of this issue? This is not a question of proper national level rules or methodology but it affects the fundamental approach of the EU level legislation. Further research may need to focus on this issue.

To sum up, international trade is a crucial issue for several reasons:

- in the case of international trade of GOs, lack of harmonization among countries leads to disclosure problems;

- the consumer awareness of the physics of electricity generation lead to scepticism regarding disclosure information;

- in the case of international trade of GOs, contradictory rules in EU level regulation lead to different statements on the same phenomena.

\subsection{Driving new RES development}

Several papers analysed the question whether GOs and green electricity products can drive new investments in the generating capacity.

Theoretically, it is obvious that green electricity products based on GOs may contribute to new RES capacities. Selling GOs provides RES generators with additional income, therefore it is an advantage to them in market competition against conventional power plants. Based on this concept, the European Commission (2016) states that an improved market of GOs "should help supplement or possibly in the longer term supersede public support for renewable energy". Raadal et al. (2012) also conclude that green electricity products might contribute to the development of RES electricity generation. Furthermore, Wüstenhagen and Bilharz (2006) add that green electricity markets can better drive cost reduction in RES generation than feed-in tariff support. Markard and Truffer (2006: 318) state that green electricity market "is more compatible with a liberalized market environment" than support schemes.

However, a number of papers conclude that the concept mentioned above does not work in practice. Markard and Truffer (2006) accomplished an analysis of five European markets (Germany, Netherlands, Sweden, Switzerland, United Kingdom). They realized that price premiums on these free markets of green electric- 
ity products are so low that their incentive effect on building new RES generating capacities is little. Boardman and Palmer (2007) focused only on the market of the United Kingdom and concluded that disclosure does not drive any change on the production side. According to the latest results, no such market development has occurred that could trigger any substantial change in this regard. Raadal et al. (2012) compared the Swedish and Norwegian green electricity markets and disclosure system with the tradable green certificate (TGC) support scheme. While TGC could bring a significant change in generating capacity, GOs and disclosure have had no effect on the production side. Hast et al. (2015) made an assessment on the green electricity markets of Finland, Germany, and the United Kingdom. According to their conclusions, green electricity products based on GOs cannot bring new RES capacities, because the large amount of GOs from already existing RES power plants creates oversupply and reduces prices. Usually large Norwegian, Swiss and Austrian hydropower generators, that were commissioned decades ago and their costs had been returned beforehand, are responsible for the oversupply. The price premium calculated by the authors is therefore rather low, around $0-5 \%$. Similarly, low premium was calculated by Mulder and Zomer (2016), who focused on the Dutch GO market. They also state that the effect of GOs on new RES development is weak and the reason for this is the high share of imported Norwegian GOs with low marginal costs. GOs are used rather just as a marketing instrument by suppliers. Dagoumas and Koltsakis (2017) conducted an econometric analysis on Greece and confirmed that prices of GOs are by far not enough to provide incentive signals for investors. A panel data analysis on a sample of 30 European countries also does not find a significant relationship between the consumer market for green electricity products supported by GOs and RES development (Hamburger - Harangozó 2018).

So, according to the consensual judgement of the literature, green electricity products based on GOs could not bring any incentives for new RES development. The reasons behind this defect are oversupply on the markets and therefore low prices. Oversupply emerges due to the large amount of import from old hydro power plants. This issue might be connected to the high share of Norwegian GOs on the market mentioned in the previous subsection. Another reason for the failure in driving new RES capacities might be that support schemes provide a more reliable incentive than voluntary GO demand (Markard - Truffer 2006; Raadal et al. 2012). Either way, if GOs and disclosure cannot excite a mechanism that brings new RES capacities, the legitimacy of the legal framework will be weakened (Aasen et al. 2010). Again, enabling limitless international trade is a barrier for promoting RES generation. 


\section{CONTRAST BETWEEN FLOWS OF ELECTRICITY AND ATTRIBUTES}

According to the literature reviewed in the previous section, the usage of GOs faces heavy challenges with regards to informing final consumers and driving new RES development. An important issue in both fields is the international trade of GOs. Regarding consumer information, lack of harmonization causes discrepancies in case of international trade but also consumer's approach to electricity in its physical form results in mistrust if GOs are traded between countries. Additionally, in case of international trade of GOs, a contradiction between EU level rules on GOs and energy statistics causes that the disclosure and statistical statements produce different information on electricity consumption. Regarding RES development, a large share of GOs from a few countries with good natural endowments bring prices down and hinder price signals towards investors. Based on these conclusions from the previous section, an investigation with the scope of international trade of GOs follows.

An empirical analysis was conducted on physical electricity flows and the international trade of GOs among AIB member countries. Although electricity market liberalization has been fulfilled in all countries and international trade of electricity became possible (see Section 2), this still does not mean that electricity can be delivered from one country to another without any limit. The business flows of electricity are limited to the available physical capacities of the interconnector networks. Traders should participate on auctions for these capacities (Van den Bergh 2015). These capacities allocated to market participants might be even curtailed by the network operator in the case of emergency situations, according to Regulation 714/2009 of the European Parliament and of the Council. Contrary, the international trade of GOs should not be limited by any physical or legal restrictions according to the Renewable Energy Directive. Consequently, international trade of GOs may differ from physical or business electricity flows.

Since several papers pointed out that consumers realize the difference between physical electricity flows and GO trade and this results in mistrust, an analysis was conducted with empirical data to investigate to what extent the international trade of GOs differ from the physical flows of electricity. Based on empirical data, the aim of this analysis is to investigate to what extent the mistrust generated by the difference between physical and certificate flows is grounded. It also aims to examine whether a remarkable gap between the two flows can be explored. This analysis makes a significant contribution to the papers cited in the previous section, because it uses empirical data for a number of countries. The data of the European Network of Transmission System Operators (hereafter ENTSO-E) on physical flows of electricity (ENTSO-E 2019) and the data of AIB on international trade of GOs (AIB 2019) were used for this purpose. The sample contained 
19 AIB member countries. ${ }^{1}$ Monthly data were taken for the analysis from the years 2016 to 2018, leading to a total of 684 observations.

For each country and for each month the amount of physical electricity export flows in the direction to other AIB member countries were summarized. Similarly, the amount of exported GOs to other AIB countries was ascertained for each observation. This was followed by the assessment of whether the amount of exported GOs exceeds the amount of physical electricity export flow in any of the cases. According to the analysis, in 277 cases ( $40.50 \%$ of the observations), the amount of exported electricity attributes was higher than the physical flow of electricity. This is already a remarkable share, however, taking the electricity values instead of the number of observations, a much higher share appears. From the total 1212193262 MWh GO exports, 875957448 MWh were realized over the values of physical export flows. Accordingly, $72.26 \%$ of exported GOs were traded over electricity flows. The same calculation was made for import data. Import of GOs exceeded physical import flows in 209 cases, 30.56\% of all observations. From a total 1164561208 MWh of GO imports, 730389679 MWh were realized over the physical import flows. This means that $62.72 \%$ percent of imported GOs was over the physical import flows of electricity. (The country of destination in the case of exported GOs and the origin in the case of imported GOs was not known, therefore the database does not include such data. However, it is sure that if these data were available, the share of GOs traded over the electricity flows would be even higher.)

Based on these high shares of surplus, the firm statement can be formulated that the flows of international GO trade are highly different from physical electricity flows. Figure 3 indicates how many GOs were exported to other AIB countries and how much the share of GO surplus is over physical flows. Figure 4 indicates the same information for import.

Looking at Figures 3 and 4, the following country-specific information can be drawn:

- In the case of export 11, in the case of import 8 countries have more than $30 \%$ surplus of GO trade over physical flows.

- The case of Norway is remarkable, since the amounts are the largest in export and import as well and the share of GO surplus is very high for both directions too. $90.08 \%$ of exported and $94.86 \%$ of imported GOs were over

1 Two AIB member countries were dropped from the sample. Belgium was dropped because the regional organizations of Belgium are members of the AIB independently and data on GOs are accessible separately for the regions. ENTSO-E data are given for countries, therefore, GO flows from and to Belgian regions cannot be compared to the physical electricity flows. Lithuania was also dropped, since it was only a member of AIB for six months of the period under analysis. 


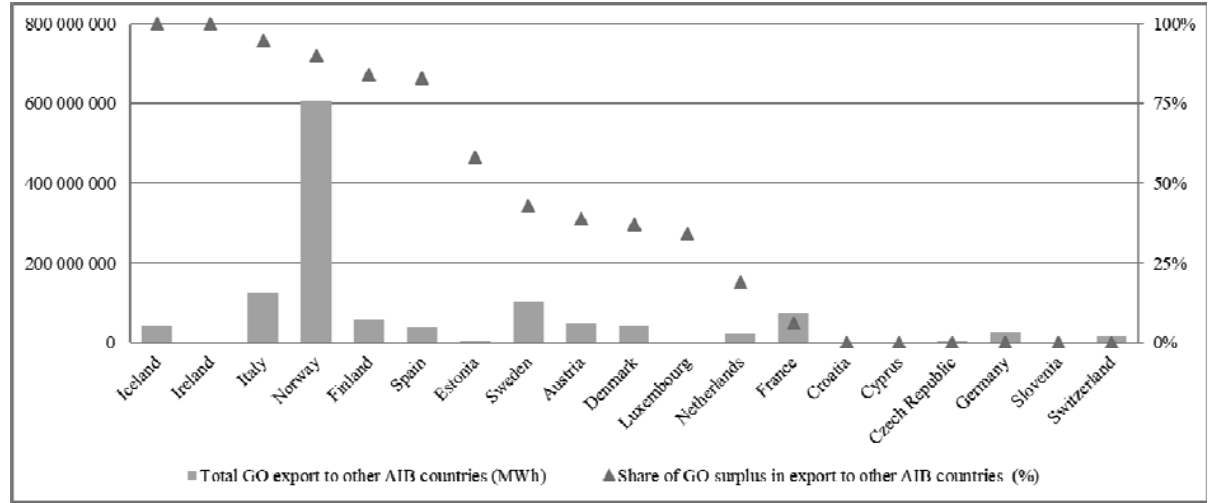

Figure 3. GO export and share of GO surplus in export to other AIB countries Source: authors.

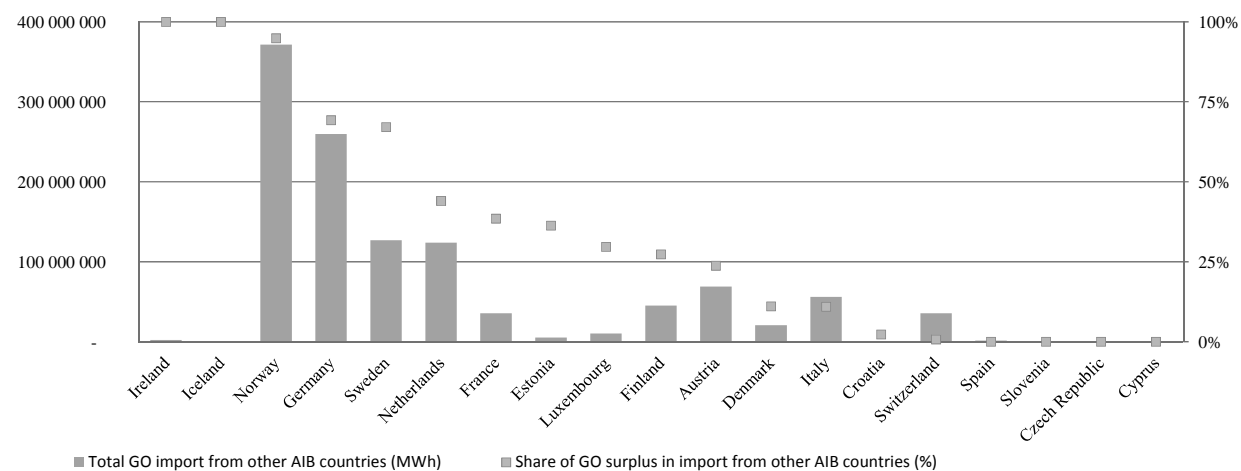

Figure 4. GO import and share of GO surplus in import from other AIB countries Source: authors.

the real physical electricity flows. Taking the absolute values, $50.03 \%$ of all exported GOs to 19 countries were from Norway. This information supports the conclusions (Hast et al. 2015; Mulder - Zomer, 2016) saying that Norwegian GOs overflow the markets.

- One of the most important GO importers is Germany. 69.24\% of this import was over the physical flow.

- Cyprus, Iceland and Ireland have no physical interconnection to other AIB countries. Cyprus and Iceland have no interconnectors at all. No physical 
flows are possible from or to these countries. However, Iceland is a significant exporter of GOs among these countries.

- In the case of three countries (Cyprus, Czech Republic, Slovenia), GO flows never exceeded the physical flows. In the case of three countries (Croatia, Germany, Switzerland), the GO export flows never exceeded the physical export.

Regarding the physical flows and the international trade of GOs, the following conclusions can be drawn:

- It is clear that the international flow of GOs is the multiple of international physical flows.

- Considering that the interconnector capacities are highly exploited (Spiridonova 2016), the quantities of traded electricity attributes are much higher than what could ever be realized in physical flows with the present interconnector capacities.

- In several cases, GO trade even occurs from or to countries lacking any interconnector capacities.

GOs are also traded outside of AIB countries. According to data from the website of AIB, in the years under analysis, a number of GOs were exported from AIB member countries to several other European countries, but also to such far away lands as Australia, Brazil, Chile, China, India, Japan, Qatar, Thailand, Saudi Arabia, the United Arab Emirates, and the United States. Market actors who trade GOs are obviously ready to utilize such opportunities to penetrate these markets. If GOs are exported to a third country, the domestic residual mix will contain a lower RES share. But in reality, it might be incomprehensible to imagine how a consumer in the Far East paying for RES GOs could affect the residual mix of a European consumer. It is doubtful that this practice fits with the legislative aims of GOs set in the Renewable Energy Directive. Consumers get information on their energy mix that is biased by consumer demand in distant countries. Although the share of GOs exported outside AIB member countries is currently low, this practice includes a fundamental distortion. It is also questionable if European consumers are aware of this practice.

Based on the regulations, the literature review, and the empirical data, several defects were identified regarding GOs that set back the realization of the aims that were formulated in the Renewable Energy Directive. These defects result in unreliable disclosure information and hinder incentivising investments. Until EU level rules remain the same, the improvement of national level regulations cannot help solve the fundamental problems. The next section summarizes recommendations of other papers and aims to articulate certain personal recommendations regarding the framework of GOs. 


\section{DISCUSSION AND POLICY RECOMMENDATION}

The international trade of GOs enabled by EU level regulations fits the approach of a common European market. The rules on international GO trade, however, do not refer to the costs and barriers of transferring energy. Furthermore, the disclosure information based on GOs is also contradictory to the official statistics. Based on these rules, a virtual trade of GOs emerged in the past years which is unable to be a basis for informing consumers, although that would be the aim of using GOs. Several papers identified that even those consumers who pay for RES electricity products do not understand or do not believe the disclosure information (Aasen et al. 2010; Winther - Ericson, 2013; Klimscheffskij et al. 2015; Jansen 2017). These rules may drive away consumers from purchasing RES electricity products. Although several papers and organizations (Bröckl et al. 2011; BEUC 2016; Jansen et al. 2016) suggest merely the improvement of communication and supporting better consumer understanding of the system, this cannot be a solution. A practice that is so distant from reality should not be communicated as real, instead, the rules should be enclosed to physical reality. Some of the papers referred to in Section 3 identify one or more issues regarding the disclosure information based on GOs, and make suggestions on regulatory framework. Klimscheffskij et al. (2015) suggest improvements on methodologies. Other papers (Lise et al. 2007; Raadal et al. 2009; Bröckl et al. 2011; Gkarakis - Dagoumas 2016) recommend stronger harmonization among states. These recommendations aim at national level regulations to provide more precise disclosure information while respecting the EU level framework. However, this EU level framework caused the flows of GOs to become rolled away from physical reality, as shown in Section 4. Even if all national methodologies and rules were precise and a full harmonization was fulfilled among European countries, the difference between physical reality and the trade of GOs would remain unchanged. And if this remains unchanged, nothing prevents the framework against consumer mistrust.

The usage of GOs also does not succeed in incentivizing new investments. The cause behind this failure is not mistrust, but low prices on the market due to a large amount of GOs from Norway and other countries with good natural endowments for RES electricity generation (Hast et al. 2015; Mulder - Zomer 2016). Data introduced in this paper verifies this opinion. Several studies recognized that GOs cannot bring more investments; therefore a different type of amendment might be needed. Hast et el. (2015: 1381) recognized that GOs cannot incentivize investments and in order to handle this problem suggested that "more attention should be paid on ensuring that price premiums paid by voluntary consumers are efficiently used to finance environmental benefits that would not otherwise 
occur”. Mulder and Zomer (2016) have more concrete suggestions. First, they recommend to allow trade of GOs only in EU countries. This way, the Norwegian GOs would be locked out of the market. This suggestion tries to solve an actual problem - namely the dump of Norwegian GOs -, however, does not address the fundamental issues of the framework. Second, they suggest that only new power plants could get GOs for their electricity generation. This suggestion aims to boost the investment motivating effect of GOs. But GO is only a tool of informing consumers and if only new power plants got GOs, it would not fit the definition of GOs. This might be a sufficient solution but then the present concept of GOs would not be valid anymore and policy makers would need to rethink it.

Based on the findings of the previous section, this paper also formulates recommendations. Of course, harmonization of national regulations, as others also have suggested, is necessary to handle reliability issues in the case of international trade of GOs. But it would not be enough, because the failures of both legislative aims result from the limitless international trade of GOs. Consumers may not believe or do not understand disclosure statements based on GOs, especially if they are aware of the physical characteristics of electricity and of the contradictions in the EU level regulation. Also, limitless international trade allows Norwegian GOs to dump the market and push down prices. These findings challenge the current EU level framework on GOs.

Physical barriers of the transportation of electricity should be taken into account. This is the case in electricity trade as well where market participants have to compete for interconnector net capacities. Electricity trade is separated from the physical flows, but physical flows and infrastructure remain barriers in the international trade of electricity and market participants have to take part in auctions for interconnector capacities. Similarly, a methodology should be elaborated that ensures that GO trade also considers physical reality. The basis of such a methodology could be the metered electricity flows on the interconnectors in a given time period, e.g. a month. Market players willing to transfer GOs from one country to another should acquire the empowerment for the transfer through a tendering process. The maximum limit for the amount of GOs enabled to transfer through an interconnector in a time period should fit the amount of realized electricity flow on that interconnector during the given period. This restriction should be applied for borders within Europe or the AIB member states and also in the direction of third countries. Export to distant countries would not be possible. The elaboration of the detailed rules might be the subject of another research. This amendment would only allow a physically realistic amount of GOs to be traded between countries and therefore consumers would get more reliable disclosure information. The GO dump from Norway would also be cut down to a lower level; therefore, market prices might be higher and might be able to incentivize 
investors. Of course, the recommended framework would be in conflict with the interest of traders, but could help to realize policy goals.

Another issue is how the problem of contradicting disclosure information and official statistics can be resolved. Even if the allowed amount of international GO trade would be adjusted to physical flows of electricity, a difference would remain between official statistics and GO information. Taking consumer understanding into consideration, it is extremely important to avoid such inconsistencies. As Wiser (1998) and Markard and Truffer (2006) also point out, education is a crucial point in the functioning of green energy markets. Markard and Truffer (2006) add that one important outcome of such markets is an eco-learning process of consumers and market participants. Nevertheless, it is clear that contradictory information hinders learning. Policy makers and further research should focus on this issue and ensure that inconsistency between the two kinds of information could be avoided.

\section{CONCLUSION}

The lack of harmonization, inaccurate national regulations, and also the present EU level regulatory framework on GOs and disclosure lead to consumers not receiving reliable information on the energy mix of their electricity consumption. Enabling the limitless trade of GOs and the contradiction between EU regulations on GOs and statistics result in unreliable energy mix disclosure information for consumers. We suggest that the possible amount of international GO trade should be determined and adjusted to physical electricity flows. This would help to provide reliable information for consumers. However, a major concern is that the new directive 2018/2001/EU on the promotion of the use of energy from renewable sources did not change the framework in this regard.

This paper identifies some problems that might be in the scope of researchers and policy makers in the future. They may determine the details of the framework and proper methodology of tendering for international trade of GOs that was proposed in the previous section. Further research should focus on the contradiction between the rules on GOs and official statistics. 


\section{REFERENCES}

Aasen, M. - Westskog, H. - Wilhite, H. - Lindberg, M. (2010): The EU Electricity Disclosure from the Business Perspective - A Study from Norway. Energy Policy 38(12): 7921-7928.

Association of Issuing Bodies (2018): European Energy Certificate System - Principles and Rules of Operation. Release 7 V.10. Arnhem: Loep ontwerp.

Association of Issuing Bodies (2019): Activity Statistics. https://www.aib-net.org/aib_activity_ statistics, accessed 10/09/2019.

Bertoldi, P. - Huld, T. (2006): Tradable Certificates for Renewable Electricity and Energy Savings. Energy Policy 34(2): 212-222.

BEUC (2016): Trustworthy 'Green Electcitiy’ Tariffs. Policy Recommendations for More Transparency, Better Choice and Environmental Benefits. Brussels: Bureau Européen des Unins de Consommateurs AISBL.

Boardman, B. - Palmer, J. (2007): Electricity Disclosure: The Troubled Birth of a New Policy. Energy Policy 35(10): 4947-4958.

Bröckl, M. - Pesola, A. - Vehviläinen, I. - Tommila, P. (2011): Guarantees of Origin and EcoLabeling of Electricity in the Nordic Countries - Final Report. Helsinki: Gaia Consulting Oy.

Chuang, J. - Lien, H. - Den, W. - Iskandar, L. - Liao, P. (2018): The Relationship Between Electricity Emission Factor and Renewable Energy Certificate: The Free Rider and Outsider Effect. Sustainable Environment Research 28(6): 422-429.

Csutora, M. - Harangozó, G. (2017): Twenty Years of Carbon Accounting - A Review and Outlook. Society and Economy 39(4): 459-480.

Dagoumas, A. S. - Koltsaklis, N. E. (2017): Price Signal of Tradable Guarantees of Origin for Hedging Risk of Renewable Energy Sources Investments. International Journal of Energy Economics and Policy 7(4): 59-67.

Draeck, M. - Timpe, C. - Jansen, J. - Schoots, K. - Lescot, D. (2009): The State of Implementation of Electricity Disclosure and Guarantees of Origin Across Europe. 6th International Conference on the European Energy Market (EEM 2009). Leuven: IEEE, pp. 1-8.

European Commission (2000): Proposal for a Directive of the European Parliament and of the Council on the Promotion of Electricity from Renewable Energy Sources in the Internal Electricity Market. Official Journal of the European Communities 311: 320-327.

European Commission (2008): Impact Assessment - Document Accompanying the Package of Implementation Measures for the EU's Objectives on Climate Change and Renewable Energy for 2020. Commission Staff Working Document.

European Commission (2016a): Impact Assessment - Accompanying the Document Proposal for a Directive of the European Parliament and of the Council on the Promotion of the Use of Energy from Renewable Sources. Commission Staff Working Document.

European Commission (2016b): Proposal for a Directive of the European Parliament and of the Council on the Promotion of the Use of Energy from Renewable Sources. https://ec.europa.eu/ energy/en/news/commission-proposes-new-rules-consumer-centred-clean-energy-transition, accessed 01/03/2018.

European Commission (2016c): Proposal for a Directive of the European Parliament and of the Council on Common Rules for the Internal Market in Electricity. https://ec.europa.eu/energy/ en/news/commission-proposes-new-rules-consumer-centred-clean-energy-transition, accessed 01/03/2018.

European Network of Transmission System Operators (2019): Physical Energy \& Power Flows. https://www.entsoe.eu/data/power-stats/physical-flows/, accessed 10/09/2019. 
Gillenwater, M. (2008): Redefining RECs - Part 1: Untangling Attributes and Offsets. Energy Policy 36(6): 2109-2119.

Gkarakis, K. - Dagoumas, A. (2016): Assessment of the Implementation of Guarantees of Origin (GOs) in Europe. In: Mavromatakis, F. - Siderakis, K. (eds): Engineering and Industry. Budapest: Trivent Publishing.

Hamburger, Á. - Harangozó, G. (2018): Factors Affecting the Evolution of Renewable Electricity Generating Capacities: A Panel Data Analysis of European Countries. International Journal of Energy Economics and Policy 8(5): 161-172.

Hanimann, R. - Vinterbäck, J. - Mark-Herbert, C. (2015): Consumer Behaviour in Renewable Electricity: Can Branding in Accordance with Identity Signalling Increase Demand for Renewable Electricity and Strengthen Supplier Brands? Energy Policy 78(C): 11-21.

Hast, A. - Syri, S. - Jokiniemi, J. - Huuskonen, M. - Cross, S. (2015): Review of Green Electricity Products in the United Kingdom, Germany and Finland. Renewable and Sustainable Energy Reviews 42(C): 1370-1384.

Jamasb, T. - Pollitt, M. (2005): Electricity Market Reform in the European Union: Review of Progress Toward Liberalization \& Integration. The Energy Journal 26: 11-41.

Jansen, J. (2017): Does the EU Renewable Energy Sector Still Need a Guarantees of Origin Market? CEPS Policy Insight No. 2017-27.

Jansen, J. - Drabik, E. - Egenhofer, C. (2016): The Disclosure of Guarantees of Origin: Interactions with the 2030 Climate and Energy Framework. CEPS Special Report.

Joskow, P. L. (2008): Lessons Learned from Electricity Market Liberalization. The Energy Journal 29(S2): 9-42.

Kaenzig, J. - Heinzle, S. L. - Wüstenhagen, R. (2013): Whatever the Customer Wants, the Customer Gets? Exploring the Gap Between Consumer Preferences and Default Electricity Products in Germany. Energy Policy 53(C): 311-322.

Klimscheffskij, M. - Van Craenenbroeck, T. - Lehtovaara, M. - Lescot, D. - Tschernutter, A. Raimundo, C. - Seebach, D. - Timpe, C. (2015): Residual Mix Calculation at the Heart of Reliable Electricity Disclosure in Europe - A Case Study on the Effect of the RE-DISS Project. Energies 8(6): 4667-4696.

Kumar, R. - Agarwala, A. (2013): Energy Certificates REC and PAT Sustenance to Energy Model for India. Renewable and Sustainable Energy Reviews 21(C): 315-323.

Lipp, J. (2001): Policy Considerations for a Sprouting UK Green Electricity Market. Renewable Energy 24(1): 31-44.

Lise, W. - Timpe, C. - Jansen, J. C. - ten Donkelaar, M. (2007): Tracking Electricity Generation Attributes in Europe. Energy Policy 35(11): 5855-5864.

Markard, J. - Truffer, B. (2006): The Promotional Impacts of Green Power Products on Renewable Energy Sources: Direct and Indirect Eco-Effects. Energy Policy 34(3): 306-321.

Mulder, M. - Zomer, S. P. E. (2016): Contribution of Green Labels in Electricity Retail Markets to Fostering Renewable Energy. Energy Policy 99(C): 100-109.

Pogutz, S. - Micale, V. (2011): Sustainable Consumption and Production - An Effort to Reconcile the Determinants of Environmental Impact. Society and Economy 33(1): 29-50.

Raadal, H. L. - Nyland, C. A. - Hanssen, O. J. (2009): Calculation of Residual Electricity Mixes When Accounting for the EECS (European Electricity Certificate System) - The Need for a Harmonised System. Energies 2(3): 477-489.

Raadal, H. L. - Dotzauer, E. - Hanssen, O. J. - Kildal, H. P. (2012): The Interaction Between Electricity Disclosure and Tradable Green Certificates. Energy Policy 42(C): 419-428. 
RE-DISS (2015): Reliable Disclosure in Europe: Status, Improvements and Perspectives. Final Report from the Project "Reliable Disclosure Systems for Europe - Phase II". Freiburg: ÖkoInstitut e.V.

Salmela, S. - Varho, V. (2006): Consumers in the Green Electricity Market in Finland. Energy Policy 34(18): 3669-3683.

Spiridonova, O. (2016): Transmission Capacities and Competition in Western European Electricity Market. Energy Policy 96(C): 260-273.

Stern, N. (2007): The Economics of Climate Change. Cambridge: Cambridge University Press.

Van den Bergh, K. - Boury, J. - Delarue, E. (2016): The Flow-Based Market Coupling in Central Western Europe: Concepts and Definitions. The Electricity Journal 29(1): 24-29.

Van der Linden, N. H. - Bürger, V. - Rivero Garcia, F. - Green, J. - Jansen, J. C. - Timpe, C. Uyterlinde, M. A. - Vrolijk, C. - White, S. - Yerro, G. P. (2004): Guarantees of Origin as a Tool for Renewable Energy Policy Formulation. EU Altener Programme.

Winther, T. - Ericson, T. (2013): Matching Policy and People? Household Responses to the Promotion of Renewable Electricity. Energy Efficiency 6(2): 369-385.

Wiser, R. H. (1998): Green Power Marketing: Increasing Customer Demand for Renewable Energy. Utility Policy 7(2): 107-119.

Wüstenhagen, R. - Bilharz, M. (2006): Green Energy Market Development in Germany: Effective Public Policy and Emerging Customer Demand. Energy Policy 34(13): 1681-1696.

Wüstenhagen, R. - Markard, J. - Truffer, B. (2000): Green Electricity in Switzerland: Insights in Market Development and Eco-Labelling. Paper prepared at the conference on "ConsumerDriven Green Electricity in Competitive Electricity Markets”, Copenhagen, May 22-23, 2000.

Zoric, J. - Hrovatin, N. (2012): Household Willingness to Pay for Green Electricity in Slovenia. Energy Policy 47: 180-187.

Open Access. This is an open-access article distributed under the terms of the Creative Commons Attribution 4.0 International License (https:/creativecommons.org/licenses/ by/4.0), which permits unrestricted use, distribution, and reproduction in any medium, provided the original author and source are credited, a link to the CC License is provided, and changes - if any - are indicated. (SID_1) 